\title{
Surgical Clips Migration up to Renal Collecting System from Ileal Conduit Postcystectomy
}

\author{
Hani Albadawi, MBBS, ${ }^{1}$ Tarik Emre Sener, MD, ${ }^{2,3}$ and Saeed Bin Hamri, MD ${ }^{1,3}$
}

\begin{abstract}
This is a 49-year-old female known to have had cystectomy and ileal conduit 4 years ago presented to our hospital complaining of left flank pain with recurrent urinary tract infection. Radiologic investigations showed left lower pole renal stone. She underwent left laser flexible ureterorenoscopy. Renal collection system was fully explored that showed stone occupying the lower calix, laser disintegration of the stone revealed what we assumed are surgical clips.
\end{abstract}

Keywords: flexible ureterorenoscopy, laser, cystectomy

\section{Introduction}

$\mathbf{U}$

RINARY DIVERSION HAS well-known morbidity and mortality rates. Major complications have been reported up to $56 \%$ in ileal conduits and up to $57 \%$ in continent catheterizable pouches. ${ }^{1}$ Bacteriuria was found in $50 \%-90 \%$ of urinary diversions that lead to increase the risk of urinary stone formation. ${ }^{1}$ Managing these stones represents a real challenge. Huge advances in endourologic miniaturizations increased the tendency of stone treatment. Retrograde approach in urinary diversions may be technically feasible using ureteral access sheath. ${ }^{2}$ The incidence of renal stones secondary to surgical clips from cystectomy and ileal conduit has not been reported; to our knowledge this is the first reported case of such identity.

\section{Case Report}

This is a 49-year-old female known to have cystectomy and ileal conduit in 2012. She presented to our clinic complaining of left recurrent flank pain with recurrent urinary infections. Physical examination revealed a good ileal pouch. Renal function test was within normal. Abdomen CT scan showed left lower pole renal stone with a burden of $16.4 \mathrm{~mm}$ (Fig. 1). The patient underwent left laser flexible ureterorenoscopy (L-FURS) through her ileal conduit (Fig. 2). Stone laser fragmentation was completely achieved, surprisingly the stone was formed over what we assume were surgical clips from the previous surgery (Fig. 3).

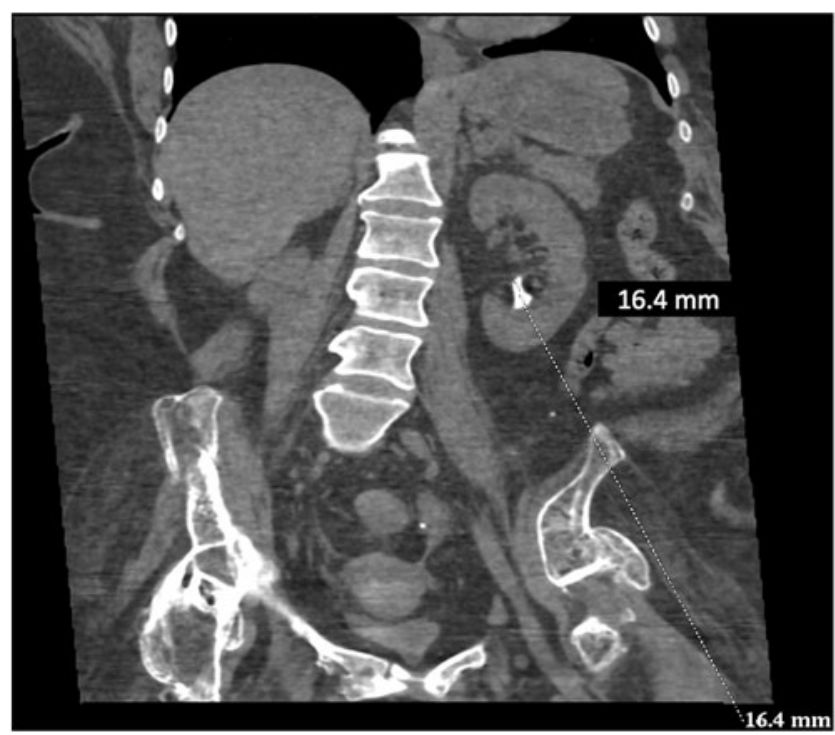

FIG. 1. CT scan showing the left renal stone.

\section{Discussion}

Urinary stone is a real dilemma in patients with urinary diversions. Shock wave lithotripsy, retrograde intrarenal surgery, and percutaneous nephrolithotomy were commonly used. With the advances in endourology, retrograde access is

\footnotetext{
${ }^{1}$ Department of Urology, King Abdulaziz National Guard Hospital, Riyadh, Saudi Arabia.

${ }^{2}$ Department of Urology, Marmara University, Istanbul, Turkey.

${ }^{3}$ PETRA-Urogroup, Paris, France.
}

(C) Hani Albadawe et al. 2016; Published by Mary Ann Liebert, Inc. This Open Access article is distributed under the terms of the Creative Commons License (http://creativecommons.org/licenses/by/4.0), which permits unrestricted use, distribution, and reproduction in any medium, provided the original work is properly credited. 

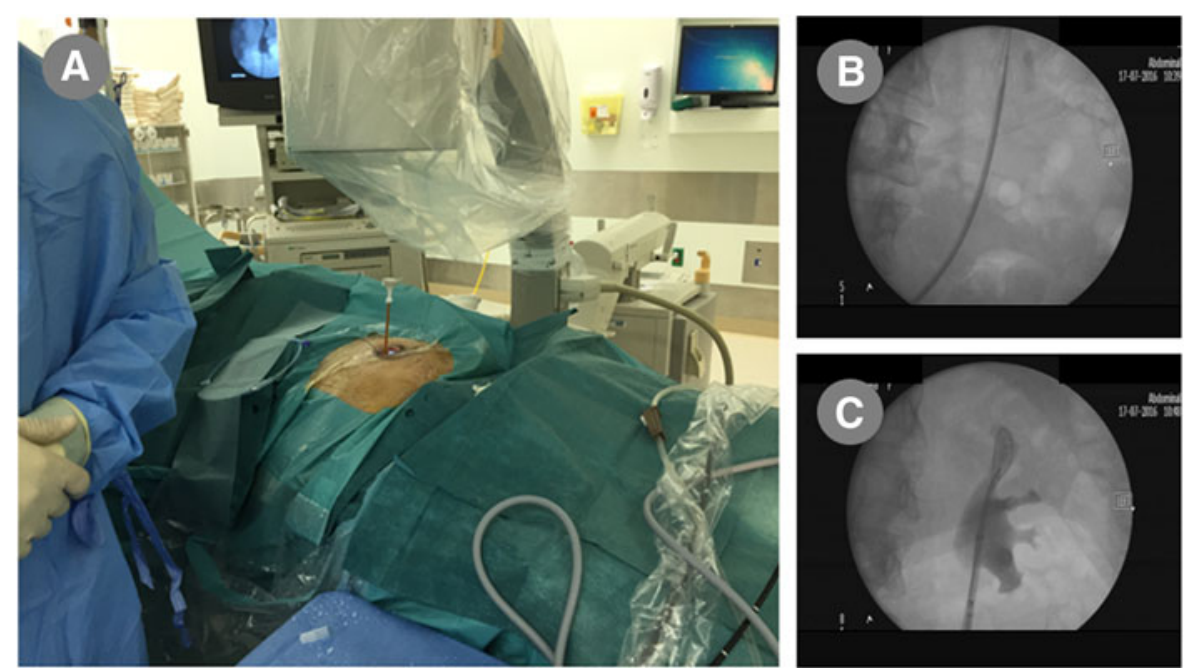

FIG. 2. (A) Ureteral access sheath through ileal conduit up to the upper ureter, (B) ureteral access

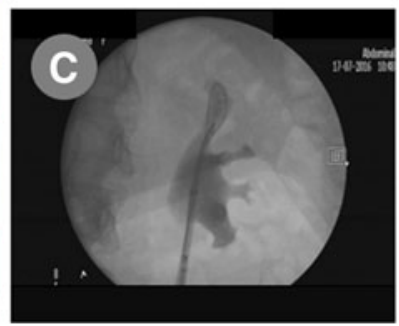
sheath (fluoroscopy) and radiopaque stone, $(\mathbf{C})$ renal collecting system full exploration.
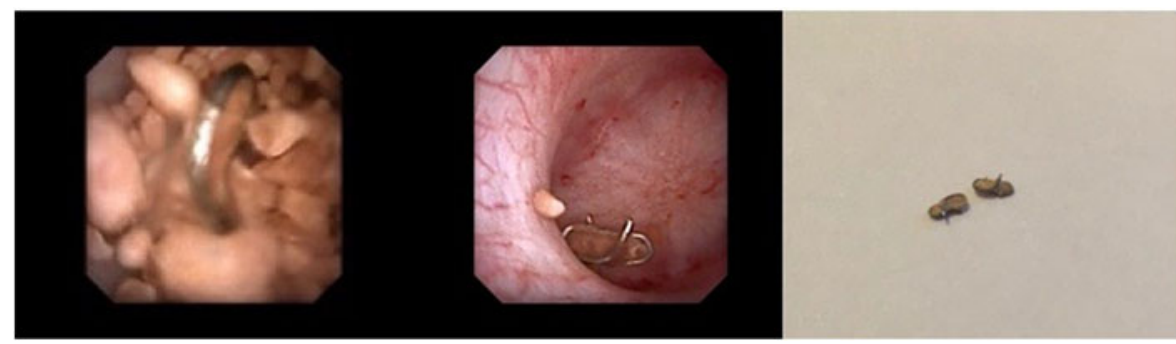

FIG. 3. Surgical clips were found postlaser disintegration of left renal stone.

now commonly used to treat such pathology. ${ }^{2}$ Regular follow-up is mandatory to prevent recurrence; moreover, metabolic changes have to be observed closely. Nevertheless, there are some reported cases of migration of surgical clips into the upper urinary tract as nidus for stone formation. ${ }^{3-5}$ Our patient's renal stone formation over surgical clips postcystectomy with ileal conduit is the first in the world.

\section{Conclusion}

Retrograde L-FURS procedure in patients presenting with renal stone as late complication of urinary diversion is safe with low morbidity rates. Metal clips may migrate postoperatively and cause complications such stone formation as well as infection. Therefore, they should be avoided and applied selectively; moreover, urologists should think of this as a cause of renal stone posturinary diversions.

\section{Disclosure Statement}

No competing financial interests exist.

\section{References}

1. Nieuwenhuijzen JA, de Vries RR, Bex A, et al. Urinary diversions after cystectomy: The association of clinical factors, complications and functional results of four different diversions. Eur Urol 2008;53:834-844.

2. Delvecchio FC, Kuo RL, Iselin CE, Webster GD, Preminger GM. Combined antegrade and retrograde endoscopic approach for the management of urinary diversion-associated pathology. J Endourol 2000;14:251-256.
3. Shu-Xiong Z., Zhen-Sheng Z., Xiao-Wen Y., Hui-Zhen L., Xin L., Ying-Hao S., Chuan-Liang X.. Intraneobladder hemo-lok migration with stone formation after orthotopic neobladder cystectomy. Case Rep Urol 2014;2014:872989.

4. Golomb J, Fuchs G, Klutke CG, Stenzl A, Raz S. Kidney stone formed around refluxed surgical staple and removed by transureteral endoscopic manipulation. Urology 1991;38:338-340.

5. Tugcu V, Polat H, Ozbay B, Eren GA, Tasci AI. Stone formation from intravesical Hem-o-lok clip migration after laparoscopic radical prostatectomy. J Endourol 2009;23:1111-1113.

Address correspondence to:

Saeed Bin Hamri, MD

Department of Urology

King AbdulAziz National Guard Hospital

Riyadh 11426

Saudi Arabia

E-mail: sbinhamri@gmail.com

Abbreviations Used
$\mathrm{CT}=$ computed tomography
L-FURS $=$ laser flexible ureterorenoscopy

Cite this article as: Albadawi $\mathrm{H}$, Sener TE, Bin Hamri S (2016) Surgical clips migration up to renal collecting system from ileal conduit postcystectomy, Journal of Endourology Case Reports 2:1, 238-239, DOI: 10.1089/ cren.2016.0121. 